"Cash management practices of small, medium and micro enterprises in the Cape Metropolis, South Africa"

\begin{tabular}{|c|c|c|}
\hline AUTHORS & $\begin{array}{l}\text { Samuel Tabot Enow } \\
\text { Peter Kamala }\end{array}$ & \\
\hline ARTICLE INFO & \multicolumn{2}{|c|}{$\begin{array}{l}\text { Samuel Tabot Enow and Peter Kamala (2016). Cash management practices of } \\
\text { small, medium and micro enterprises in the Cape Metropolis, South Africa. } \\
\text { Investment Management and Financial Innovations, 13(1-1), 230-236. } \\
\text { doi:10.21511/imfi.13(1-1).2016.10 }\end{array}$} \\
\hline DOI & \multicolumn{2}{|c|}{ http://dx.doi.org/10.21511/imfi.13(1-1).2016.10 } \\
\hline RELEASED ON & \multicolumn{2}{|l|}{ Friday, 08 April 2016} \\
\hline JOURNAL & \multicolumn{2}{|c|}{ "Investment Management and Financial Innovations" } \\
\hline FOUNDER & \multicolumn{2}{|c|}{ LLC "Consulting Publishing Company "Business Perspectives" } \\
\hline & & $\begin{array}{l}=-= \\
= \pm=\end{array}$ \\
\hline NUMBER OF REFERENCES & NUMBER OF FIGURES & NUMBER OF TABLES \\
\hline
\end{tabular}

(C) The author(s) 2023. This publication is an open access article. 
Samuel Tabot Enow (South Africa), Peter Kamala (South Africa)

\title{
Cash management practices of small, medium and micro enterprises in the Cape Metropolis, South Africa
}

\begin{abstract}
The aim of this research article is to investigate the cash management practices of small, medium and micro enterprises (SMMEs) in the Cape Metropolis, in South Africa. Data are collected from a sample of 200 SMMEs by means of a closed-ended questionnaire survey. The findings of the study revealed that most of the sampled SMMEs manage their cash effectively. However, only a minority of these entities hold cash for speculative purposes or even invest their surplus cash gainfully, thus, they fail to optimize on their scarce cash resources. Likewise, only a minority of the SMMEs employ computers for managing their cash, which is rather surprising given the proliferation of computers at a low cost in South Africa.
\end{abstract}

Keywords: cash management, SMMEs, decision-makers, practices.

JEL Classification: $M$.

\section{Introduction}

Cash is the lifeblood of every business, big and small alike (Abioro, 2013). A business may be profitable and yet without cash to meet its obligation as they fall due will be forced to close down (Enow 2015). By contrast, a loss making business may still continue to operate if it has cash. Effective cash management does not only increase chances of survival of a business, it also helps to attract investors who can fund its expansion, as the first thing that investors look for when evaluating a business is its cash flow, which, in turn, reflects its cash management practices (Merchant Factors, 2013). In addition, effective cash management increases the flexibility and competitive advantage of a business in dealing with emergency situations or taking advantage of opportunities as they arise, at a short notice (Gyebi \& Quain, 2013). Furthermore, it enables a business to take advantage of cash discounts and avoid costly sources of finance when raising funds (Uwonda, Okello \& Okello, 2013).

Unlike big businesses, small and medium enterprises (SMMEs) operating in South Africa, SMMEs have a limited access to cash given their lack of collateral required by banks as well as a success track record (Biljon, 2015). Following the global financial crisis of 2007 to 2008, most banks, which SMMEs rely on heavily for cash borrowing, have adopted restrictive lending criteria that has dramatically reduced SMMEs' access to cash. Even as South Africa recovered from the global financial crisis, South African banks have maintained their credit-restrictive mind-sets (Merchant Factors, 2013). South African SMMEs, therefore, unlike their larger counterparts that have access to a variety

(C) Samuel Tabot Enow, Peter Kamala, 2016.

Samuel Tabot Enow, Department of Management Accounting, Cape Peninsula University of Technology, South Africa.

Peter Kamala, Dr., Department of Management Accounting, Cape Peninsula University of Technology, South Africa. of cash sources, have to manage their cash effectively if only to survive.

Notwithstanding the importance of cash and the limited access that SMMEs in South Africa experience, anecdotal evidence suggests that these entities do not seem to manage their cash effectively (Biljon, 2015). Specifically, most of these entities do not prepare cash budgets or forecasts, do not conduct bank reconciliations and do not monitor their cash flows on a real-time basis (Bruwer, 2015). Worse still, some lack bank accounts and appear to be ignorant about their liquidity (Small Business Connect, 2015). Many SMMEs also take a passive approach to their cash management, rely on manual processes or simple accounting software to manage their cash even as their businesses grow (Enow, 2015). Eventually, these businesses face liquidity problems that result in their closure.

Indeed, the failure rate of SMMEs in South Africa is reported to be one of the highest in the world as about $70 \%$ to $80 \%$ of these entities fail during their first three years of existence (Ngary, Smith, Bruwer \& Ukpere, 2014). Although prior research in other countries has partly attributed a high failure rate of SMMEs to ineffective cash management practices (Sunday, Burani \& Eliabu, 2013; Sunday, 2010; Uwonda et al., 2013), limited research has been conducted in South Africa to investigate the cash management practices of SMMEs in the country. Therefore there is a gap in research on cash management practices of South African SMMEs. Given the importance of SMMEs in creating employment opportunities that are desperately needed in South Africa, and bearing in mind the high failure rate of these entities in the country, it is imperative that their cash management practices be investigated.

This article attempts to fill in the gap in the prior literature by investigating the cash management practices of SMMEs in the Cape Metropolis, in 
South Africa. The rest of the article proceeds as follows: Section 1 reviews the relevant prior literature. Section 2 presents the methodology adopted, followed by results and discussion in Section 3. Final Section provides the summary and conclusion of the article.

\section{Literature review}

Notwithstanding the importance of cash to SMMEs and the fact that they have limited access to cash, prior studies conducted in different countries suggest that these entities do not manage their cash effectively (Pietersen, 2012; Nyamao, Patrick, Odondo \& Simeyo, 2012). A Ghanaian survey of 199 SMEs by Pietersen (2012) found that $51.3 \%$ of enterprises neither forecasted nor had a cash target for their businesses. In addition, only $32.7 \%$ of the enterprises prepared monthly cash budgets, although $65.3 \%$ of the enterprises deposited their sales proceeds on a daily basis. Furthermore, only $13.6 \%$ of enterprises re-invested their cash surpluses but $56.3 \%$ of the enterprises often spent within their budgeted limits. Pietersen (2012) observed that most SMMEs lacked financial expertise to prepare cash budgets and invest cash surplus. Although insightful, the preceding study was conducted in Ghana (West Africa) and, therefore, their findings may not be generalzable to South African SMMEs.

In a similar study, Nyamao, Patrick, Odondo and Simeyo (2012) assessed the cash management practices of 159 Kenyan Small Scale Enterprises (SSEs) and found that $60.9 \%$ of these entities seldomly prepared cash budgets and that only $23.6 \%$ of the SSEs prepared the budgets often. Unsurprisingly, most SSEs $(67.3 \%)$ did not predetermine a target cash balance in advance. Of the sampled SSEs, 56.4\% regularly experienced cash surpluses but they did not invest the surpluses in short term investments. Nyamao et al. (2012) concluded that most Kenyan SSEs had cashmanagement problems. Nyamao et al. (2012) study was conducted in Kenya, therefore, its findings may not be generalizable to South African SMMEs.

A related questionnaire survey by Masoud and Mbega (2012) on cash management practices of 16 Tanzanian small businesses found that $68.8 \%$ of these entities did not prepare cash budgets. Only $6.3 \%$ of small businesses pre-determined a target cash balance in advance. Like in Nyamao et al. (2012) study, $50 \%$ of the small businesses always experienced cash shortages and $56.2 \%$ did not invest their cash surpluses in short term investments. Furthermore, only $31.3 \%$ of the businesses deposited their cash surpluses in bank accounts. Masoud and Mbega (2012) concluded that a lack of financial knowledge was a major cause of ineffective cash management in small businesses in
Tanzania. Given that Masoud and Mbega's (2012) study used a small sample size, its findings may not be generalizable to all Tanzanian small businesses let alone the South African SMMEs.

In yet another East African, Sunday et al. (2013) assessed the cash management practices of 386 Small and Medium Entities (SMEs) in western Uganda. Sunday et al. (2013) found that the cash management practices of Ugandan SMEs were weak and that most of these entities experienced frequent cash shortages due to a failure to prepare cash budgets on a monthly basis. In addition, only a few SMEs had a cash surplus and those that did, did not invest it in interest-bearing accounts.

Another Ugandan study by Uwonda et al. (2013) on cash-flow management of 120 SMEs found that $41.8 \%$ of these entities did not prepare cash budgets and that another $20.33 \%$ did not even monitor their cash flow. Only $59 \%$ adhered to their cash budgets but $33 \%$ disregarded budgetary controls. In addition, $53.3 \%$ of SMEs did not prepare a bank reconciliation statement. The preceding two studies were conducted in Uganda, thus, their findings may not be generalizable to South African SMMEs.

No study could be found on cash management practices of South African SMMEs. This, alongside the above-mentioned gaps in the prior literature, suggests a need for a recent study to investigate the cash management practices of South African SMMEs. This study aims to fill in the gap in the literature by investigating the cash management practices of SMMEs in the Cape Metropolis, in South Africa.

\section{Methodology}

2.1. Questionnaire design. The perceptions of the decision-makers of SMMEs that comprised owners, managers and accountants on the cash management of their businesses were elicited using a questionnaire survey. A closed-ended questionnaire was designed that comprised fourteen questions in two sections, namely, section $\mathrm{A}$ and $\mathrm{B}$. The questionnaire which was in form of multiple-choice or yes/no questions was designed to be easy to answer, a strategy deployed to maximize the response rate by minimizing the time required to complete it, which ideally should have been 15 minutes.

Section A of the questionnaire elicited information on a respondent's personal profile as well as the respondent's business profile. This section which comprised five questions, elicited information such as respondent's position in the business, gender, accounting educational background, number of years the SMME has been operating and number of employees of the SMME. This information was 
meant to ensure that the selected respondents were owners, managers or accountants of an SMME and thus the appropriate to participate in this study.

Section B elicited information on cash-management practices of a respondent's business. This section comprised 9 questions that required a "yes" or "no" response. Respondents were required to indicate if their businesses had a bank account, conducted bank reconciliation, prepared cash budgets, predetermined its cash shortage or surplus, invested cash surpluses, held cash for speculative purposes, monitored cash flows regularly, used computers to manage cash in their day-to-day operations and spent cash as planned.

Before distributing the questionnaire, a pilot test was conducted whereby the questionnaires were completed and critically evaluated by ten academics with vast experience in questionnaire design. The questionnaires were then adjusted according to the recommendations of the academics and when resubmitted to them were found to be clear, concise and understandable.

2.2. Population and sample selection. The population comprised owners, managers and accountants of SMMEs operating in the Fast Moving Consumer Goods (FMCG) Sector in the Cape Metropolis as these were deemed to be the decision-makers of SMMEs that ought to be familiar with the cash management practices of the entities. A target sample of 200 FMCG SMMEs was set given a lack of a comprehensive list of all SMMEs operating in the Cape Metropolis. To achieve this target, 270 respondents were approached. An accidental-sampling technique was employed to select the sample given that it advocates the drawing of a sample from the part of the population that is conveniently accessible to the researcher (Collis \& Hussey, 2003).

2.3. Questionnaire distribution. On completion of the pilot test, the data collection process commenced with the identification of potential respondents. The researcher and the seven other trained researchers visited the premises of the potential respondents, explained the purpose of the study, the research methodology employed, and ethical considerations such as anonymity of respondents, confidentiality of information divulged as well as the limited risk in participating in the research. The potential respondents were, then, requested to indicate their willingness to participate in the study. Where the potential respondents agreed to participate, the researcher administered the questionnaire by reading the questions to the respondents and recorded their responses by marking them with an " $\mathrm{X}$ " in the appropriate box of the questionnaire.

\subsection{Response rate and test for non-response bias.} Out of the 270 respondents that were approached to participate in this survey, 220 agreed to participate in the survey. Thus, 220 questionnaires were completed, 20 of which were found to be incomplete and were, thus, withdrawn from the sample. Therefore, out of the 270 potential respondents that were initially approached, only 200 completed usable questionnaires resulting in a response rate of $74.07 \%$.

To minimize the effect of a non-response bias, different respondents that ranged from owners, managers and accountants, male and female, from different industries were approached and encouraged to participate in the survey. In addition, the profile of the respondents as well as that of their businesses was analyzed and found to indicate that respondents of different persuasions had answered the questionnaire (De Villiers \& Van Staden, 2010). Furthermore, respondents were persuaded to participate in the survey using the face to face approach even if they had little interest in cash management practices (De Villiers \& Van Staden, 2010). Given the large number of respondents of 200, a high response rate and diverse respondents, the risk for non-response bias was minimized.

\section{Results and discussions}

\subsection{Respondents' personal and their business's profile.}

Table 1. Respondents' personal and their business's profile

\begin{tabular}{|c|c|c|}
\hline & $\begin{array}{l}\text { Number of } \\
\text { respondents }\end{array}$ & Percentage \\
\hline \multicolumn{3}{|c|}{ Position in the business: } \\
\hline Owner & 136 & $68 \%$ \\
\hline Manager & 45 & $22 \%$ \\
\hline Accountant & 2 & $1 \%$ \\
\hline Supervisor & 17 & $9 \%$ \\
\hline Total & 200 & $100 \%$ \\
\hline \multicolumn{3}{|l|}{ Gender: } \\
\hline Male & 137 & $68.5 \%$ \\
\hline Female & 63 & $31.5 \%$ \\
\hline Total & 200 & $100 \%$ \\
\hline \multicolumn{3}{|c|}{ Accounting background: } \\
\hline Seminars & 22 & $11 \%$ \\
\hline Short course & 42 & $21 \%$ \\
\hline Diploma & 22 & $11 \%$ \\
\hline Degree & 14 & $7 \%$ \\
\hline Masters & 4 & $2 \%$ \\
\hline None & 95 & $48 \%$ \\
\hline Total & 200 & $100 \%$ \\
\hline \multicolumn{3}{|c|}{ Age of the business: } \\
\hline Less than 2 years & 14 & $7 \%$ \\
\hline $2-5$ years & 105 & $52.5 \%$ \\
\hline $6-10$ years & 52 & $26 \%$ \\
\hline
\end{tabular}


Table 1 (cont.). Respondents' personal and their business's profile

\begin{tabular}{|l|c|c|}
\hline & $\begin{array}{c}\text { Number of } \\
\text { respondents }\end{array}$ & Percentage \\
\hline More than 10 years & 29 & $14.5 \%$ \\
\hline Total & 200 & $100 \%$ \\
\hline Number of employees: & 153 & $76.5 \%$ \\
\hline 1 to 5 employees & 47 & $23.5 \%$ \\
\hline 6 to 50 employees & 200 & $100 \%$ \\
\hline Total &
\end{tabular}

The respondents were asked to provide information on their personal profiles relating to their position in the business, gender and accounting-education background. The purpose of this information was to ensure that the appropriate respondents had been selected to participate in the survey and also to ensure that respondents of different characteristics and persuasions participate in the survey in order to minimize non-response bias.

Of the respondents, $68 \%$ were owners, $22 \%$ were managers, $1 \%$ was accountants and $9 \%$ were supervisors (see Table 1). Given that $91 \%$ of the respondents were either owners or managers, it can be concluded that the appropriate respondents were selected to participate in the survey. Concerning the gender of the respondents, $68.5 \%$ were male while $31.5 \%$ were female.

With regard to the accounting-education background of the respondents, $48 \%$ did not have any accounting-education background whatsoever (see Table 1). Of the respondents, $21 \%$ had attended a short course in accounting, while $11 \%$ had attended accounting seminars. A similar percentage (11\%) had a diploma in accounting, whereas $7 \%$ had a bachelor's degree. Only $2 \%$ had a master's degree in accounting. In short, the management of working capital was basically undertaken by decision-makers with limitedto-no formal accounting knowledge.

As far as how long the respondents' businesses are concerned, $52.5 \%$ of the respondents indicated that their SMMEs were two to five years old, while $26 \%$ indicated that their SMMEs were six to 10 years old; $14.5 \%$ indicated that their SMMEs were more than 10 years old, while only $7 \%$ indicated that their SMMEs were less than two years old (see Table 1). Given that SMMEs that are two years old or more are expected to have developed sound cash management practices, one would expect that the respondents' SMMEs should have developed these practices as $93 \%$ of them were at least two years old.

Concerning the number of employees, the findings indicate that $76.5 \%$ of the respondent's SMMEs had one to five employees, while $23.5 \%$ had six to 50 employees. In the South African context, the former can be classified as micro enterprises while the latter were classified as small enterprises. Therefore, this study focused only on the cash management practices of small and micro enterprises.

\subsection{Cash management practices of SMMEs.} Respondents were asked to indicate by a way of a yes or no question whether their SMMEs had a bank account, conducted bank reconciliation, prepared cash budgets, pre-determined its cash shortage or surplus, invested cash surpluses, held cash for speculative purposes, monitored cash flows regularly, used computers to manage cash in their day-to-day operations and spent cash as planned.

3.2.1. Whether businesses have a business bank account. As summarized in Table 2, 62\% of the respondents indicated that their businesses had a bank account, while 38\% indicated that their businesses did not have the same. A Binomial Test (2-tailed) conducted revealed a significant difference was found between the proportion of the respondents whose businesses had a bank account $(62 \%)$, and the proportion of those whose businesses did not have a bank account $(38 \%)(p<0.05)$.

The above results are consistent with the findings of Sunday, Uwonda et al. (2013), and Yiadom and Agyei (2006) who also found that most of the smallscale enterprises in Uganda and Ghana had a business bank account, but in contrast to the findings of Nguyen (2001) which found that only $19 \%$ of SMEs in Vietnam had a cash surplus deposited in a bank account. A possible explanation for the difference is that Nguyen's (2001) study was conducted in 2001 when SMEs were still ignorant of the benefits of business bank accounts.

\subsubsection{Whether businesses conducted bank} reconciliation. As shown in Table 2, 53\% of the respondents whose business had a business bank account indicated that their businesses conduct bank reconciliations, while $47 \%$ indicated that their businesses did not do the same. Based on the Binomial Test (2-tailed) conducted, a significant difference was found between the proportion of the respondents whose businesses conduct bank reconciliations $(53 \%)$ and those whose businesses did not $(47 \%)(p<0.05)$. It is rather disappointing that almost half of the respondents' businesses did not conduct bank reconciliations, which is critical for uncovering irregularities such as unauthorized withdrawals and ensuring that a business's transactions have been recorded correctly. The preceding results of this study are consistent with the findings of Sunday et al. (2013) who found that most SMEs in western Uganda did not conduct bank reconciliations. 
Table 2. Cash management practices of SMMEs

\begin{tabular}{|l|c|c|c|c|}
\hline & Yes & No & $\mathrm{N}$ & $p$-value \\
\hline 1. Have a bank account & $62 \%$ & $38 \%$ & 200 & $0.001^{*}$ \\
\hline 2. Conduct bank reconciliation & $53 \%$ & $47 \%$ & 124 & $0.00^{*}$ \\
\hline 3. Prepare a cash budget & $60.5 \%$ & $39.5 \%$ & 200 & $0.004^{*}$ \\
\hline $\begin{array}{l}\text { 4. Have a way to pre-determine } \\
\text { cash shortage/surplus }\end{array}$ & $68.5 \%$ & $31.5 \%$ & 200 & $0.00^{*}$ \\
\hline 5. Invest cash surplus & $40.5 \%$ & $59.5 \%$ & 200 & $0.009^{*}$ \\
\hline $\begin{array}{l}\text { 6. Hold cash to take advantage } \\
\text { of investment opportunities }\end{array}$ & $41 \%$ & $59 \%$ & 200 & $0.013^{*}$ \\
\hline $\begin{array}{l}\text { 7. Monitor cash outflow on } \\
\text { regular basis }\end{array}$ & $73.5 \%$ & $26.5 \%$ & 200 & $0.00^{*}$ \\
\hline $\begin{array}{l}\text { 8. Use computers to manage } \\
\text { cash }\end{array}$ & $35 \%$ & $65 \%$ & 200 & $0.00^{*}$ \\
\hline 9. Spend cash as planned & $62.5 \%$ & $37.5 \%$ & 200 & $0.00^{*}$ \\
\hline
\end{tabular}

Note: * statistically significant differences $(p<0.05)$ at $95 \%$ confidence level.

3.2.3. Whether businesses prepared cash budgets. As illustrated in Table $2,60.5 \%$ of the respondents indicated that their businesses prepared cash budgets, while $39.5 \%$ indicated that their businesses did not do the same. Considering the importance of cash budgets in enabling business entities to determine their future cash needs and in decisions such as the credit terms to extend to debtors without facing liquidity problems, it is rather disappointing that quite a significant percentage $(39.5 \%)$ of SMMEs did not prepare these budgets. The Binomial Test (2-tailed) conducted revealed a significant difference between the proportion of the respondents whose businesses prepared cash budgets $(60.5 \%)$ and those whose businesses did not $(39.5 \%)(p<0.05)$.

The preceding results of this study are consistent with the findings of Nguyen (2001) and MensahAgyei (2012) who found that most SMEs prepared cash budgets on a monthly basis. However, the results of the current study contrast those of Yiadom and Agyei (2006), Pietersen (2012), and Masoud and Mbega (2012) who found that most SMEs did not prepare cash budgets. A possible explanation for the difference is that South African SMMEs may have had the financial knowledge required to prepare cash budgets, perhaps due to Government intervention, that may have been lacking in the other African countries.

3.2.4. Whether businesses have a way to predetermine cash shortages/surplus. As summarized in Table 2, 68.5\% of the respondents indicated that they had a way to pre-determine cash shortages/surpluses but $31.5 \%$ indicated that they did not. A Binomial Test (2-tailed) conducted revealed a significant difference between the proportion of the respondents who indicated that their businesses had a way to pre-determine cash shortages/surpluses $(68.5 \%)$ and those whose businesses did not $(31.5 \%)(p<0.05)$.
By comparing the results of this question to those of the previous question, an interesting observation can be made that $8 \%$ of the businesses had an alternative way of pre-determining their cash shortage or surplus other than by using cash budgets. The preceding results of the current study contrast with those of Pietersen (2012) and Nyamao et al. (2012) who found that most small enterprises neither forecasted nor had a cash target for their business. A possible explanation for the difference between this study and those of Pietersen (2012) and Nyamao et al. (2012) is that most of the South African SMMEs in the current study had prepared cash budgets and used them to determine cash shortages/surpluses, unlike the SMEs in the two preceding studies.

\subsubsection{Whether businesses invest their cash surplus.}

As disclosed in Table 2, 40.5\% of the respondents indicated that their businesses invested their cash surpluses, while $59.5 \%$ did not. A Binomial Test revealed a significant difference $(p<0.05)$ between the proportion of the respondents whose businesses invest cash surpluses $(40.5 \%)$ and those whose businesses did not $(59.5 \%)$. The preceding results suggest that a majority of the sampled SMMEs did not optimize on the utilization of their resources, and are consistent with the findings of Nguyen (2001), Pietersen (2012), Mensah-Agyei (2012), and Nyamao et al. (2012) who found that most SMEs did not invest their cash surpluses.

\subsubsection{Whether businesses hold cash to take} advantage of investment opportunities. As shown in Table 2 , only $41 \%$ of the respondents indicated that their businesses held cash to take advantage of investment opportunities, while $59 \%$ indicated that their businesses did not do the same. A Binomial Test revealed a significant difference $(p<0.05)$ between the proportion of the respondents whose businesses held cash to take advantage of investment opportunities (41\%) and those whose businesses did not (59). Considering the relative difficulty faced by SMMEs when raising cash for investment purposes, the preceding results suggest that SMMEs may have been foregoing a low cost source of capital in favor of more costlier sources when pursuing business opportunities.

\subsubsection{Whether businesses monitor their cash flow} on regular basis. As summarized in Table 2, 73.5\% of respondents indicated that their businesses monitored their cash flows on a regular basis, while $26.5 \%$ indicated that their businesses did not do the same. The Binomial Test (2-tailed) conducted revealed a significant difference $(p<0.05)$ between the proportions of the respondents whose businesses monitored their cash flow on a regular basis $(73.5 \%)$ and those whose businesses did not (26.5\%). The 
preceding results are not surprising given the advancements in information technology in South Africa that has enabled banks to provide businesses with an update of their bank account balances after each transaction.

The preceding results are consistent with the findings of Sunday et al. (2013) who found that most SMMEs ensure the safeguarding of cash and have efficient internal control systems in place to monitor their cash. However, the results of the current study contrast with those of Sunday et al. (2013) who found that most SMMEs do not have internal control systems in place to monitor their cash. A possible explanation for the difference between the current study and that of Sunday et al. (2013) is that the latter study was conducted in a remote part of Uganda, an area likely to have a limited access to advanced information technology.

\subsubsection{Whether businesses use computers to manage} their cash. Only $35 \%$ of the respondents indicated that their businesses made use of computers to manage cash, while $65 \%$ of the respondents indicated that their businesses did not (see Table 2). The Binomial Test (2-tailed) conducted revealed a significant difference between the proportion of the respondents whose businesses used computers to manage cash (35\%) and those whose businesses did not $(65 \%)(p<0.05)$. The preceding results are rather disappointing considering the proliferation of computers at low cost that can enable businesses to manage their cash more effectively. These results are consistent with the findings of Pietersen (2012) and Sunday et al. (2013) who found that most SMMEs did not use computers to manage cash.

3.2.9. Whether businesses spend cash as planned. As summarized in Table 2, 62.5\% of the respondents indicated that their businesses spent cash as planned whereas $37.5 \%$ of the respondents indicated that their businesses did not spend cash as planned. Given that only $60.5 \%$ had prepared cash budgets, the above results suggest that $2 \%$ of the sampled businesses may have used some type of cash budgets, though they did not refer to the budgets as cash budgets. The above results also suggest that most of the sampled businesses controlled their expenditure, an attribute vital for the survival of SMMEs given their limited access to cash. The Binomial Test (2-tailed) conducted revealed a significant difference was found $(p<0.05)$ between the proportion of the respondents who indicated that their businesses spent cash as planned (62.5\%) and those whose businesses did not (37.5\%). The above results of this study are consistent with the findings of Uwonda et al. (2013) who found that most SMMEs adhere to budgets by ensuring that expenditure is explained and justified.

\section{Summary and conclusion}

The aim of this article was to determine the cash management practices of SMMEs, in the Cape Metropolis in South Africa. The results of the article show that $62 \%$ of the sampled SMMEs have a bank account. Of these, only $53 \%$ conduct bank reconciliation. The results also show that $60.5 \%$ of the sampled SMMEs prepare cash budgets but $68.5 \%$ have a way to pre-determine a cash shortage or surplus. This together with the fact that $62.5 \%$ spend cash as planned suggests that some SMMEs are able to pre-determine their cash shortages or surpluses, and even spend money as planned without having to prepare a cash budget. The results further indicate that $73.5 \%$ of the sampled SMMEs monitor cash outflows on a regular basis. By contrast, only $41 \%$ of the SMMEs hold cash to take advantage of investment opportunities. Indeed only $40.5 \%$ of the entities invest their cash surplus. Worse still, only $35 \%$ of the sampled SMMEs use computers to manage cash.

Although the above results suggest that most SMMEs manage their cash effectively, the fact that only a minority of SMMEs hold cash for speculative purposes or even invest surplus cash suggests that they are not optimizing their utilization of this scarce resource. This could imply that either the decision-makers of SMMEs are ignorant of the available short-term investment opportunities or they simply are not generating a cash surplus that can be invested. Given the proliferation of computers at a low cost, it is rather surprising that only a minority use them for managing their cash. This could be attributed to the prevalence of computer illiteracy among most decision-makers of SMMEs, particularly the micro enterprises. For SMMEs to optimize cash management which will further enhance the wealth of their businesses, they should invest their cash surpluses in profitable investments.

The findings of this article have implications for decision-makers of SMMEs as they will be made aware of the benefits of managing their cash effectively, particularly with regard to the need to use computers to manage cash, need to hold cash for speculative purposes and the need to invest cash surplus in the various short term investment opportunities available. They may have to take regular training and workshops on the abovementioned aspects of effective cash management practice, which currently they seem lacking. The South African Government may also draw from the findings of this study when developing interventions meant to increase the survival rate of SMMEs by facilitating training workshops that focus on cash management skills of decision-makers of SMMEs through the Small Enterprise Development Agency. 


\section{References}

1. Abioro, M. (2013). The impact of cash management on the performance of manufacturing companies in Nigeria, Uncertain Supply Chain Management, 1 (3), pp. 177-192.

2. Biljon, V. (2015). SA SMEs struggle with cash flow as a result of delayed payment. Available at: http://www.businesspartners.co.za/media-room/press-releases/posts [Accessed 14 October 2015].

3. Bruwer, J.P. (2010). Sustainability of South African FMCG SMME retail businesses in the Cape Peninsula. Unpublished Master of Technology Thesis. Cape Town. Cape Peninsula University of Technology.

4. Bruwer, J.P. (2015). The Usefulness of Cash Budgets in Micro, Very Small and Small Retail Enterprises Operating in the Cape Metropolis, Expert Journal of Business and Management, 3 (1), pp. 1-12.

5. Collis, J. \& Hussey, R. (2003). Business Research: A practical guide for undergraduate and post graduate students. Palgrave: Macmillan.

6. De Villiers, C.J. \& Van Staden, C.J. (2010). Shareholders' corporate environmental disclosure need, South African Journal of Economic and Management Sciences, 13 (4), pp. 436-445.

7. Enow, S. (2015). The working capital management practices of small medium and micro enterprises in the Cape Metropolis. Unpublished Master of Technology Thesis. Cape Town. Cape Peninsula University of Technology.

8. Enow, S. and Brijlal, P. (2014). The effect of working capital management on profitability: the case of Small, Medium and Micro enterprises in South Africa, Journal of Accounting and Management, 4 (2), pp. 7-15.

9. Gyebi, F., Quain, S. (2013). Internal Control on cash collection.A case of the electricity company of Ghana ltd, Accra East region, International Journal of Business and Social Science, 4 (9), pp. 217-233

10. Masoud, S.M. and Mbega, M. (2012). An exploratory study of SMES' Working-capital Management practices in Dar es Salaam. Proceedings of 13th International Conference on African Entrepreneurship \& Small Business Development, 20-21 $1^{\text {st }}$ June, Dar es Salaam.

11. Mensah-Agyei, B.K. (2012). Working Capital Management practices of small firms in the Ashanti region of Ghana, International journal of academic research in business and social science, 2 (1), pp. 3781-3789.

12. Merchant Factors. (2013). Finance beyond the numbers. Available at: http://www.mfactors.co.za/articles .php\#2 [Accessed 14 October 2015].

13. Ngary, C., Smith, Y., Bruwer, J.P. and Ukpere, W.I. (2014). Financial performance measures and business objective attainment in Fast Food SMMEs in Cape Metropolis: A preliminary liability and suitability analysis, Mediterranean journal of social science, 5 (20), pp. 909-919.

14. Nguyen, K.M. (2001). Financial management and profitability of small and medium enterprises. Publish dissertation submitted for Doctor of Business Administration. Southern Cross University.

15. Nyamao, N.R., Patrick, O., Martin, L., Odondoand Simeyo, O.A.J. (2012). Effect of working capital management practises on financial performance: A study of Small scale enterprises in Kisii South District, Kenya, African Journal of Business Management, 6 (18), pp. 5807-5817.

16. Uwonda, G., Okello, N., Okello, N.G. (2013). Cash flow management utilization by Small Medium Enterprises (SMEs) in Northern Uganda, Merit Research Journal of Accounting, Auditing, Economics and Finance, 1 (5), pp. 67-80.

17. Pietersen, A. (2012). Working Capital Management practices of Small and Medium Enterprises in the Western Region: A survey of selected Smes in the Sekondi-Takoradi Metropolis. Published Dissertation submitted for Masters of Business administration. Kwame Nkrumah University of Science and Technology.

18. Small Business Connect. (2015). Help on the way for township entrepreneurs. Available at: http://www.small businessconnect.co.za/news. [Accessed 14 October 2015].

19. Sunday, A., Burani, A. and Eliabu, B. (2013). Financial Management practices in small and medium Enterprises in selected Districts in western Uganda, Research Journal of Finance and Accounting, 1 (2), pp. 29-42.

20. Sunday, K.J. (2010). Effective working capital management in small and medium scale Enterprises, International Journal of Business and management, 6 (9), pp. 271-279.

21. Yiadom, E.M. and Agyei, S.K. (2006). Working Capital Management practices of Small scale Enterprises in the central region of Ghana, Asian Journal of Business and Management Science, 1 (4), pp. 29-47. 